\title{
Características morfo-anatômicas e bromatológicas de folhas de amoreira em relação às preferências do bicho-da-seda
}

\author{
Fumiko Okamoto(1) e Roberto Antonio Rodella(2)
}

\begin{abstract}
(1)Unidade de Pesquisa e Desenvolvimento de Gália, Caixa Postal 16, CEP 17470-000 Gália, SP. E-mail: updgalia@aptaregional.sp.gov.br (2)Universidade Estadual Paulista "Julio de Mesquita Filho", Instituto de Biociências de Botucatu, Caixa Postal 510, CEP 18618-000 Botucatu, SP. E-mail: rodella@ibb.unesp.br
\end{abstract}

Resumo - O objetivo deste trabalho foi avaliar, quantitativamente, as características morfo-anatômicas e bromatológicas das folhas de dez cultivares de amoreira, e estabelecer as relações de preferência do bicho-daseda, por essas cultivares. Foram coletadas as folhas superior (5ำ e mediana (15aㅡ) da planta, contadas a partir do ápice. As cultivares foram comparadas pelos métodos estatísticos multivariados de análise de agrupamento e análise de componentes principais. As cultivares Korin, Calabresa, IZ 5/2 e IZ 15/7 foram consideradas as mais recomendáveis para a alimentação das lagartas do bicho-da-seda, pois apresentaram valores altos de porcentagem de folha consumida, atribuídos à ocorrência de características desejáveis nas folhas, tais como menor teor de fibra bruta, menor quantidade de idioblastos de cistólito e de mucilagem, menor proporção de epiderme e maior de parênquima, comparativamente, às outras cultivares estudadas. As cultivares IZ 13/6 e IZ 57/2 foram consideradas as menos recomendáveis. As demais cultivares comportaram-se como intermediárias na preferência do bicho-da-seda.

Termos para indexação: análise quantitativa, cultivares de amoreira, Morus, sericicultura.

\section{Mulberry leaf morphological, anatomical and bromatological characteristics in relation to silkworm preferences}

\begin{abstract}
The objective of this work was to evaluate quantitatively the morphological, anatomical and bromatological characteristics of leaves of ten mulberry cultivars, and to establish the preferences shown by the silkworm. The upper $\left(5^{\text {th }}\right)$ and median $\left(15^{\text {th }}\right)$ leaves were collected taking branch top into account. In order to compare cultivars, multivariate statistic methods of cluster analysis and principal component analysis were used. The cultivars Korin, Calabresa, IZ 5/2 and IZ 15/7 were considered as the most appropriate to feed silkworms, since they presented high percentage values of eaten leaves, due to certain characteristics such as lower crude fiber contents, lower quantity of cystolith and mucilage idioblasts, lower proportions of epidermis and higher quantities of parenchyma, in relation to the other studied cultivars. Cultivars IZ 13/6 and IZ 57/2 were considered as less recommendable. The other cultivars formed an intermediate group, in relation to silkworm preferences.
\end{abstract}

Index terms: quantitative analysis, mulberry cultivars, Morus, sericulture.

\section{Introdução}

Existem 35 espécies de amoreira, distribuídas nas diversas regiões do globo terrestre, das quais Morus alba L., M. lhou Koidz e M. bombycis Koidz são as mais freqüentes (Fonseca \& Fonseca, 1988).

A exploração da cultura da amoreira visa, principalmente, sua utilização na nutrição das lagartas do bicho-da-seda (Bombyx mori L.), que se alimentam exclusivamente de suas folhas. Hazama (1968) caracterizou as folhas da amoreira, por meio de medidas do comprimento, largura e espessura.
A espessura da folha contribui consideravelmente na manutenção da turgescência, nos períodos compreendidos entre a colheita dos ramos e o armazenamento no depósito de folhas, e durante o tempo em que as folhas permanecem sobre as esteiras de criação até o consumo pelas lagartas do bicho-da-seda. Segundo Okino (1982), esta espessura varia em função da variedade e da forma de cultivo.

Metcalfe \& Chalk (1957) caracterizaram a anatomia foliar de plantas da família Moraceae, tendo constatado, na epiderme de Morus spp., a presença de idioblastos de mucilagem e de cistólitos, que estão relacionados com 
a função de proteção contra a herbivoria (Fahn, 1979) e representam, portanto, a porção foliar não desejável para alimentação das lagartas do bicho-da-seda. Katsumata (1971) e Fujita \& Uchikawa (1986) também observaram idioblastos de cistólitos na epiderme foliar de amoreira.

Cappellozza et al. (1996) estudaram os aspectos anatômicos das folhas de dez cultivares de amoreira e destacaram a presença de idioblastos de cistólito na epiderme da face adaxial, e de idioblastos de mucilagem em ambas as faces da epiderme. Concluíram que o número de cistólitos afeta a palatabilidade da folha e a sua concentração aumenta com o amadurecimento dela. Observações semelhantes foram verificadas em trabalho realizado por Sugimura et al. (1999).

São escassos os trabalhos que relacionam a anatomia foliar de amoreira com a composição bromatológica. Entretanto, para plantas forrageiras, especialmente gramíneas, tais trabalhos são numerosos, o que possibilita determinar o valor nutricional das plantas, conforme Rodella et al. (1982, 1984), Akin (1989), Wilson (1993), Jung \& Allen (1995), Brito et al. (1997a, 1997b, 1999, 2003, 2004), Ventrella et al. (1997) e Brito \& Rodella (2002).

As cultivares de amoreira podem também diferir quanto à qualidade das folhas, ocorrendo variações em sua composição química, em função da altura de inserção da folha no ramo, do estádio de desenvolvimento da planta e de práticas de manejo (Ide, 1969; Porto \& Okamoto, 2000; Miranda et al., 2002; Porto et al., 2004).

O teor de proteína da folha de amoreira, recomendado para nutrição do bicho-da-seda, situa-se entre 20 e 30\%, de acordo com Hamano \& Okano (1989). Valores semelhantes foram também constatados por Hirano (1982), em 17 variedades japonesas, e por Thangamani \& Vivekanandan (1984), em cultivares da Índia. No Brasil, híbridos de amoreira apresentaram teores de proteína entre 21,98 e 26,60\% (Mendonça, 1994). Entretanto, o emprego de práticas de adubação pode elevar o teor para 24,8 a 28,8\% (Takahashi \& Kronka, 1989).

O objetivo deste trabalho foi avaliar, quantitativamente, as características morfológicas, anatômicas e bromatológicas das folhas de dez cultivares de amoreira, situadas em dois níveis de inserção no ramo, e estabelecer relações de preferência do bicho-da-seda por essas cultivares.

\section{Material e Métodos}

O trabalho foi conduzido na Unidade de Pesquisa e Desenvolvimento de Gália, Agência Paulista de Tecnologia dos Agronegócios (APTA) Regional Centro Oeste, da Secretaria de Agricultura e Abastecimento do Estado de São Paulo. As avaliações anatômicas e morfológicas das folhas foram efetuadas no Lab. de Morfologia e Anatomia Vegetal, do Dep. de Botânica, Inst. de Biociências de Botucatu, Unesp. A composição bromatológica foi determinada no Lab. de Forragicultura do Dep. de Nutrição e Produção Animal, da Fac. de Medicina Veterinária e Zootecnia de Botucatu, Unesp.

O solo do local do experimento foi classificado como predominantemente Argissolo Vermelho-Amarelo e apresenta baixos teores de nutrientes. A análise química do solo revelou os seguintes valores: $\mathrm{P}$ resina, $9 \mu \mathrm{g} \mathrm{cm}^{-3}$; MO, 0,6\%; $\mathrm{pH}\left(\mathrm{CaCl}_{2}\right), 4,9 ; \mathrm{V}, 34,18 \% ; \mathrm{K}$, 0,06 meq $100 \mathrm{~cm}^{-3}$; Ca, 0,6 meq $100 \mathrm{~cm}^{-3} ; \mathrm{Mg}$, 0,3 meq $100 \mathrm{~cm}^{-3}$; Al, 0,00 meq $100 \mathrm{~cm}^{-3} ; \mathrm{H}+\mathrm{Al}$, 1,8 meq $100 \mathrm{~cm}^{-3}$; SB, 0,96 meq $100 \mathrm{~cm}^{-3}$; T, 2,81 meq $100 \mathrm{~cm}^{-3}$.

Provenientes da coleção do Instituto de Zootecnia (IZ), foram utilizadas dez cultivares de amoreira (Morus spp.): Calabresa, Korin, IZ 40, IZ 64, IZ 5/2, IZ 13/6, IZ 15/7, IZ 23/3, IZ 56/4 e IZ 57/2.

Os tratos culturais foram realizados, seguindo-se as recomendações técnicas usuais de campo, de acordo com Hanada \& Watanabe (1986), tendo-se promovido a uniformização das plantas, por meio do corte ao nível do solo; efetuado o controle de plantas invasoras e de formigas cortadeiras; e aplicado adubo e corretivo, com base na análise de solo, para a manutenção da produção. As plantas apresentavam idade média de dez anos, estavam estabelecidas em espaçamento de 2,0x0,5 m e ocupavam 2 ha de área.

A amostragem do material vegetal foi realizada na primavera (novembro), em plena safra sericícola, aos 90 dias depois do corte de uniformização. Coletaram-se as lâminas foliares de dois níveis de inserção no ramo 5 e 15 a folhas, contadas a partir da primeira folha expandida do ápice, representando, respectivamente, os níveis superior e mediano do ramo. Essas folhas foram utilizadas nas avaliações morfo-anatômicas e bromatológicas.

O delineamento experimental adotado foi o de blocos ao acaso, em parcelas subdivididas, com 10 tratamentos principais (cultivares), dois tratamentos secundários (folhas superior e mediana) e três repetições. 
As características morfológicas avaliadas foram: área da lâmina foliar, porcentagem de folhas não consumidas e número total de nervuras secundárias. As mensurações da área foliar e da área da porção não consumida das folhas foram efetuadas com auxílio de integralizador automático de área. A área da porção não consumida das folhas foi transformada em porcentagem, em relação à área foliar total, tendo sido determinada depois de 30 minutos de alimentação pelas lagartas do bicho-da-seda.

Para as avaliações anatômicas foram tomadas porções da região mediana da lâmina foliar, fixando-as em FAA 50 (formaldeído + ácido acético glacial + álcool $50 \%$ ), durante 48 horas, tendo sido, posteriormente, conservadas em álcool 70\% (Johansen, 1940).

As amostras referentes às regiões da nervura secundária e internervural foram infiltradas em resina glicolmetacrilato, de acordo com a técnica de Gerrits (1991). Em seguida, os materiais foram seccionados transversalmente, em micrótomo rotatório com espessuras de 8 a $10 \mu \mathrm{m}$, na nervura secundária, e de 5 a $6 \mu \mathrm{m}$ na região internervural, e corados com azul de toluidina (O’Brien et al., 1964). Os limites e os contornos dos tecidos foram desenhados com auxílio de microscópio de projeção, tendo-se determinado as áreas por meio de mesa digitalizadora acoplada com programa computacional (Corrêa \& Rodella, 2002).

Foram mensuradas as seguintes características, com relação à nervura secundária: área da secção transversal, espessura do conjunto compreendido pela epiderme e colênquima, e porcentagem do conjunto compreendido pelo parênquima e floema. Quanto à região internervural, as características mensuradas foram: espessura da folha; porcentagem de epiderme, de idioblastos de mucilagem e de parênquima clorofiliano; número de idioblastos de mucilagem e de cistólito; e área compreendida pelo idioblasto de cistólito.

Para a determinação da composição bromatológica, coletaram-se $300 \mathrm{~g}$ de folhas, sem o pecíolo, que foram colocadas em estufa com circulação forçada de ar a $65^{\circ} \mathrm{C}$, por 72 horas. Foram determinados os teores, em porcentagem, de matéria seca, proteína bruta, fibra bruta e matéria mineral, de acordo com a metodologia descrita por Wende, citado por Silva (1981).

Os dados obtidos das 17 características morfológicas, anatômicas e bromatológicas foram submetidos aos testes estatísticos multivariados de análise de agrupamento e análise de componentes principais (Sneath \& Sokal, 1973).

\section{Resultados e Discussão}

Os valores médios referentes às características quantitativas da folha superior ( 5 a folha), das dez cultivares de amoreira, foram empregados na análise de componentes principais e de agrupamento (Tabela 1).

Na Tabela 2 estão descritos os coeficientes de correlação entre as 17 características da folha superior e os dois primeiros componentes principais $\left(\mathrm{Y}_{1} \mathrm{e} \mathrm{Y}_{2}\right)$, resul-

Tabela 1. Valores médios de 17 características morfo-anatômicas e bromatológicas da folha superior (5a folha), de dez cultivares de amoreira.

\begin{tabular}{|c|c|c|c|c|c|c|c|c|c|c|}
\hline \multirow[t]{2}{*}{ Característica quantitativa } & \multicolumn{10}{|c|}{ Cultivar } \\
\hline & Calabresa & Korin & IZ 40 & IZ 64 & $\mathrm{IZ} 5 / 2$ & IZ $13 / 6$ & $1215 / 7$ & IZ $23 / 3$ & IZ 56/4 & IZ $57 / 2$ \\
\hline Área da lâmina foliar $\left(\mathrm{cm}^{2}\right)$ & 153,72 & 178,20 & 186,17 & 157,86 & 180,11 & 180,78 & 167,35 & 137,99 & 137,49 & 269,21 \\
\hline Espessura da folha ( $\mu \mathrm{m})$ & 143,13 & 145,88 & 115,30 & 117,77 & 126,30 & 140,39 & 118,04 & 131,48 & 123,26 & 117,59 \\
\hline Folhas não consumidas (\%) & 2,01 & 14,02 & 12,59 & 21,17 & 8,26 & 33,40 & 15,57 & 31,26 & 21,15 & 37,83 \\
\hline Número de nervuras secundárias & 9,25 & 9,25 & 8,00 & 7,75 & 8,00 & 7,50 & 8,75 & 8,00 & 7,00 & 8,25 \\
\hline Área da nervura secundária $\left(\mathrm{mm}^{2}\right)$ & 0,73 & 0,41 & 0,30 & 0,29 & 0,40 & 0,74 & 0,66 & 0,36 & 0,28 & 0,54 \\
\hline Espessura epiderme + colênquima $(\mu \mathrm{m})$ & 73,89 & 63,19 & 70,48 & 62,04 & 61,90 & 105,62 & 79,40 & 62,88 & 62,14 & 81,74 \\
\hline Parênquima + floema $(\%)$ & 63,23 & 61,72 & 56,38 & 58,86 & 64,39 & 63,22 & 63,17 & 60,87 & 60,33 & 61,35 \\
\hline Epiderme $(\%)$ & 26,64 & 21,51 & 27,47 & 28,82 & 25,08 & 27,81 & 23,98 & 26,32 & 27,00 & 29,85 \\
\hline Idioblasto de mucilagem $\left(\mathrm{n}^{-} \mathrm{mm}^{-1}\right)$ & 6,83 & 5,83 & 5,50 & 5,67 & 5,83 & 7,67 & 4,33 & 7,50 & 5,83 & 9,33 \\
\hline Idioblasto de mucilagem (\%) & 4,01 & 3,12 & 3,11 & 5,05 & 3,43 & 3,83 & 2,16 & 3,86 & 3,94 & 5,97 \\
\hline Idioblasto cistólito $\left(\mathrm{n}^{\mathrm{o}} \mathrm{mm}^{-2}\right)$ & 22,00 & 23,33 & 38,33 & 27,00 & 26,33 & 27,33 & 24,67 & 28,67 & 27,00 & 40,33 \\
\hline Área de cistólito $\left(\times 10^{-3} \mathrm{~mm}^{-2}\right)$ & 2,95 & 1,64 & 1,91 & 2,41 & 1,61 & 2,46 & 2,31 & 2,60 & 2,51 & 2,18 \\
\hline Parênquima clorofiliano (\%) & 63,45 & 68,77 & 62,59 & 61,16 & 66,19 & 63,97 & 60,53 & 60,35 & 61,25 & 60,99 \\
\hline Matéria seca $(\%)$ & 26,43 & 27,51 & 28,29 & 27,52 & 26,04 & 23,72 & 26,81 & 27,95 & 27,45 & 26,47 \\
\hline Proteína bruta $(\%)$ & 21,62 & 17,87 & 18,44 & 16,84 & 17,41 & 18,38 & 19,35 & 18,40 & 16,77 & 17,70 \\
\hline Fibra bruta $(\%)$ & 8,96 & 8,33 & 9,25 & 9,21 & 9,13 & 10,23 & 8,85 & 9,64 & 8,33 & 10,24 \\
\hline Matéria mineral (\%) & 8,06 & 6,04 & 7,07 & 6,85 & 6,93 & 8,56 & 8,08 & 8,18 & 7,27 & 6,26 \\
\hline
\end{tabular}


tantes da análise de componentes principais. No conjunto, esses componentes foram responsáveis por 70,29\% da informação (variância) acumulada pelos caracteres avaliados, constituindo-se em indicadores eficientes de dissimilaridade, permitindo, portanto, diferenciar as cultivares de amoreira. A intensidade da contribuição dessas características, para a discriminação das cultivares, está relacionada à ocorrência de maiores valores absolutos em $\mathrm{Y}_{1}$ e $\mathrm{Y}_{2}$, que se caracterizam por apresentar maior poder discriminatório.

As características da folha superior que mais contribuíram para a diferenciação das cultivares, para o primeiro componente $\left(\mathrm{Y}_{1}\right)$, foram: porcentagem de folha não consumida, de fibra bruta, de idioblastos de mucilagem e de epiderme, bem como número de idioblastos de mucilagem e de idioblastos de cistólito (Tabela 2). Quanto ao segundo componente $\left(\mathrm{Y}_{2}\right)$, as características com maior poder discriminatório foram: área da secção transversal da nervura secundária, porcentagem de proteína bruta e espessura da epiderme mais colênquima da nervura secundária. $\mathrm{O}$ primeiro componente, por apresentar valor de informação retida maior que do segundo componente, foi considerado mais satisfatório, para explicar a contribuição das características avaliadas na formação dos agrupamentos das cultivares de amoreira, relacionadas à qualidade da folha superior para a alimentação das lagartas do bicho-da-seda.

Tabela 2. Coeficientes de correlação entre as 17 características morfo-anatômicas e bromatológicas da folha superior (5a folha), das dez cultivares de amoreira e os dois primeiros componentes principais $\left(\mathrm{Y}_{1}\right.$ e $\left.\mathrm{Y}_{2}\right)$.

\begin{tabular}{lrr}
\hline Característica quantitativa & \multicolumn{1}{c}{$\mathrm{Y}_{1}$} & \multicolumn{1}{c}{$\mathrm{Y}_{2}$} \\
\hline Área da lâmina foliar $\left(\mathrm{cm}^{2}\right)$ & 0,5856 & 0,0167 \\
Espessura da folha $(\mu \mathrm{m})$ & $-0,2015$ & 0,5120 \\
Folhas não consumidas $(\%)$ & 0,9416 & $-0,0628$ \\
Número de nervuras secundárias & $-0,4117$ & 0,3985 \\
Área da nervura secundária $\left(\mathrm{mm}^{2}\right)$ & 0,0928 & 0,9798 \\
Espessura epiderme + colênquima $(\mu \mathrm{m})$ & 0,4868 & 0,7349 \\
Parênquima + floema (\%) & $-0,1075$ & 0,6605 \\
Epiderme (\%) & 0,6834 & $-0,0809$ \\
Idioblasto de mucilagem $\left(\mathrm{n}^{\mathrm{o}} \mathrm{mm}^{-1}\right)$ & 0,8263 & 0,1821 \\
Idioblasto mucilagem $(\%)$ & 0,7184 & $-0,1926$ \\
Idioblasto cistólito $\left(\mathrm{n}^{\mathrm{o}} \mathrm{mm}^{-2}\right)$ & 0,6291 & $-0,3834$ \\
Área de cistólito $\left(\mathrm{x} 10^{-3} \mathrm{~mm}^{-2}\right)$ & 0,1869 & 0,4715 \\
Parênquima clorofiliano $(\%)$ & $-0,4202$ & 0,0457 \\
Matéria seca (\%) & $-0,3049$ & $-0,7052$ \\
Proteína bruta (\%) & $-0,3209$ & 0,7640 \\
Fibra bruta (\%) & 0,8109 & 0,2681 \\
Matéria mineral $(\%)$ & $-0,0264$ & 0,6531 \\
\hline Informação retida $(\%)$ & 43,29 & 27,00 \\
Informação acumulada $(\%)$ & - & 70,29 \\
\hline
\end{tabular}

O dendrograma resultante da análise de agrupamento e a dispersão gráfica referente à análise de componentes principais (Figura 1) permitiram agrupar as dez cultivares de amoreira, com base nas características morfoanatômicas e bromatológicas da folha superior, de forma que as cultivares pertencentes a um mesmo grupo apresentaram maior similaridade que aquelas de grupos diferentes. Verificou-se a formação de três grupos principais: o primeiro grupo foi formado pelas cultivares Calabresa e IZ 15/7, consideradas, pela qualidade da folha superior, como recomendáveis para a alimentação
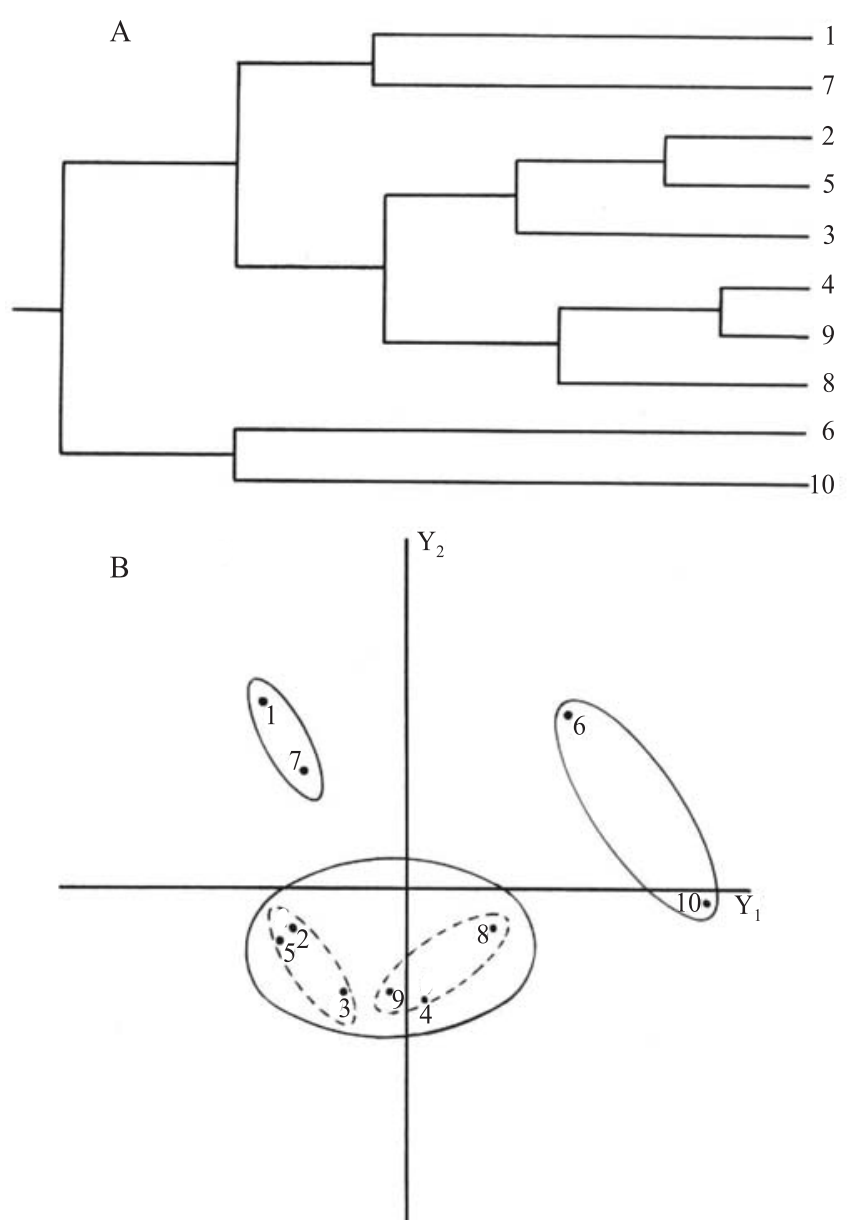

Figura 1. Dendrograma resultante da análise de agrupamento das 17 características quantitativas da folha superior (5a), utilizando-se a distância euclidiana média entre dez cultivares de amoreira (A) e dispersão gráfica das dez cultivares de amoreira (B), utilizando-se os dois primeiros componentes principais $\left(\mathrm{Y}_{1}\right.$ e $\left.\mathrm{Y}_{2}\right)$, para o conjunto das 17 características quantitativas da folha superior (5a). Cultivares de amoreira: Calabresa (1); Korin (2); IZ 40 (3); IZ 64 (4); IZ 5/2 (5); IZ 13/6(6); IZ 15/7 (7); IZ 23/3(8); IZ 56/4 (9); IZ 57/2 (10). 
das lagartas do bicho-da-seda; o segundo grupo, considerado como intermediário, foi constituído por dois subgrupos, um deles formado pelas cultivares Korin, IZ 40 e IZ 5/2, e outro foi composto por IZ 64, IZ 23/3 e IZ 56/4; o terceiro grupo foi formado por IZ 13/6 e IZ 57/2, consideradas como pouco recomendáveis.

A análise conjunta do primeiro componente (Tabela 2) e da dispersão gráfica (Figura 1) mostrou que a folha superior das cultivares IZ 13/6 e IZ 57/2 apresentou maiores porcentagens de folha não consumida, de fibra bruta, de epiderme e de idioblastos de mucilagem, números de idioblastos de mucilagem e de idioblastos de cistólito, maior espessura do conjunto epiderme mais colênquima da nervura secundária, bem como menor porcentagem de proteína bruta (Tabela 1). A presença dessas características, de acordo com Fahn (1979) e Cappellozza et al. (1996), confere às folhas maior proteção contra a herbivoria, e as torna indesejáveis para a alimentação do bicho-da-seda; conseqüentemente, essas cultivares foram consideradas como pouco recomendáveis ao consumo. Resultados contrários foram verificados em Calabresa e IZ 15/7, as quais foram consideradas recomendáveis, pois se demonstraram como forrageiras com alta qualidade da folha superior e de maior preferência para a alimentação.

Essa maior qualidade foliar, atribuída à Calabresa, também foi constatada por Takahashi (1996), que destaca a ocorrência, nesta cultivar, de elevado teor de proteína (Thangamani \& Vivekanandan, 1984; Hamano \& Okano, 1989; Mendonça, 1994), que desempenha papel fundamental nos processos metabólicos, sendo limitante para o crescimento de insetos (Scriber \& Slansky Junior, 1981) e para a produção do fio de seda (Hanada \& Watanabe, 1986). A cultivar IZ 15/7 foi também considerada recomendável ao consumo, por apresentar características quantitativas foliares desejáveis, provavelmente, pelo fato de sua progenitora feminina ser a cultivar Calabresa.

Portanto, essas cultivares podem apresentar boa produção de casulos, pois segundo Periasamy \& Radhakrishnan (1985), Mendonça (1994) e Qader (1995), um dos fatores determinantes da produção é a qualidade nutricional das folhas de amoreira, que apresenta grande importância para o crescimento das lagartas do bicho-da-seda (Tinoco \& Almeida, 1992).

As cultivares Calabresa e IZ 15/7 (do primeiro grupo), e Korin, IZ 40 e IZ 5/2 (subgrupo do segundo grupo) podem ser consideradas mais apropriadas para alimentação das lagartas, uma vez que apresentaram maior consumo foliar, o que foi atribuído, principalmente, à ocorrência de características quantitativas desejáveis na folha superior (Tabela 1). Resultados diferentes verificaram-se nas cultivares IZ 13/6 e IZ 57/2 (do terceiro grupo), que apresentaram menor consumo foliar, em virtude de presença de características não desejáveis na folha (Katsumata, 1971; Fahn, 1979; Fujita \& Uchikawa, 1986; Cappellozza et al., 1996; Sugimura et al., 1999), que tornam essas cultivares pouco recomendadas. As cultivares IZ 64, IZ 23/3 e IZ 56/4 foram consideradas como sendo de grupo intermediário, em relação à qualidade da folha superior.

Atualmente, os sericicultores pouco utilizam a Calabresa, pois de acordo com Fonseca et al. (1987), essa cultivar apresenta baixo volume de produção de folhas por ha por ano. Porém, face aos resultados obtidos, com base na qualidade da planta como forrageira, é viável o seu emprego, principalmente na alimentação de lagartas de primeiro e segundo instares, quando o volume de folhas consumidas é pequeno e a seletividade dos insetos é alta, optando as lagartas por alimentos mais palatáveis.

As médias das características quantitativas da folha mediana (15a folha), das dez cultivares de amoreira, empregadas para a realização da análise de componentes principais e análise de agrupamento, estão apresentadas na Tabela 3.

Os coeficientes de correlação entre as 17 características da folha mediana e os dois primeiros componentes principais ( $\mathrm{Y}_{1}$ e $\left.\mathrm{Y}_{2}\right)$, resultantes da análise de componentes principais, encontram-se na Tabela 4. No conjunto, estes componentes foram responsáveis por 76,10\% da informação (variância) acumulada pelos caracteres avaliados, revelando que eles são indicadores eficientes de dissimilaridade, permitindo, diferenciar as cultivares de amoreira.

Para o primeiro componente $\left(\mathrm{Y}_{1}\right)$, as características com maior poder discriminatório das dez cultivares de amoreira foram: porcentagem de folha não consumida, de parênquima clorofiliano, de epiderme, de fibra bruta e de idioblastos de mucilagem, bem como número de idioblastos de cistólito e de idioblastos de mucilagem (Tabela 4). Com relação ao segundo componente $\left(\mathrm{Y}_{2}\right)$, as características que apresentaram maior contribuição para a discriminação das cultivares foram: espessura da epiderme mais colênquima da nervura secundária, área da secção transversal da nervura secundária, porcentagem de idioblastos de mucilagem e área do idioblasto de cistólito. O primeiro componente, por apre- 
Tabela 3. Valores médios de 17 características morfo-anatômicas e bromatológicas da folha mediana ( $15^{a}$ folha), de dez cultivares de amoreira.

\begin{tabular}{|c|c|c|c|c|c|c|c|c|c|c|}
\hline \multirow[t]{2}{*}{ Característica quantitativa } & \multicolumn{10}{|c|}{ Cultivar } \\
\hline & Calabresa & Korin & IZ 40 & IZ 64 & IZ 5/2 & IZ 13/6 & IZ 15/7 & IZ 23/3 & IZ 56/4 & IZ 57/2 \\
\hline Área da lâmina foliar $\left(\mathrm{cm}^{2}\right)$ & 166,27 & 160,02 & 186,53 & 134,07 & 150,60 & 212,64 & 159,56 & 132,42 & 176,56 & 265,44 \\
\hline Espessura da folha $(\mu \mathrm{m})$ & 160,31 & 156,43 & 121,66 & 141,10 & 127,29 & 152,81 & 113,08 & 139,31 & 123,16 & 120,10 \\
\hline Folhas não consumidas (\%) & 4,65 & 6,71 & 24,46 & 26,56 & 7,16 & 25,84 & 25,63 & 21,27 & 34,66 & 29,73 \\
\hline Número de nervuras secundárias & 8,25 & 8,50 & 7,25 & 7,00 & 7,25 & 8,25 & 7,50 & 7,75 & 7,25 & 7,50 \\
\hline Área da nervura secundária $\left(\mathrm{mm}^{2}\right)$ & 0,96 & 0,51 & 0,31 & 0,34 & 0,46 & 0,71 & 0,62 & 0,42 & 0,42 & 0,77 \\
\hline Espessura epiderme + colênquima $(\mu \mathrm{m})$ & 102,20 & 64,28 & 67,20 & 66,84 & 65,01 & 94,61 & 68,05 & 66,64 & 66,01 & 89,78 \\
\hline Parênquima + floema $(\%)$ & 60,40 & 62,17 & 58,66 & 60,92 & 61,49 & 60,68 & 64,51 & 59,39 & 62,14 & 61,70 \\
\hline Epiderme (\%) & 23,69 & 19,38 & 23,04 & 25,65 & 23,47 & 26,26 & 23,44 & 21,56 & 26,29 & 26,40 \\
\hline Idioblasto de mucilagem $\left(\mathrm{n}^{\mathrm{o}} \mathrm{mm}^{-1}\right)$ & 7,00 & 7,50 & 4,33 & 9,50 & 4,50 & 9,17 & 5,85 & 7,50 & 8,50 & 10,85 \\
\hline Idioblasto de mucilagem $(\%)$ & 4,77 & 3,55 & 2,14 & 4,10 & 2,96 & 6,27 & 2,51 & 4,27 & 5,32 & 5,73 \\
\hline Idioblasto cistólito $\left(\mathrm{n}^{\mathrm{o}} \mathrm{mm}^{-2}\right)$ & 15,67 & 19,67 & 30,33 & 25,00 & 20,33 & 24,33 & 29,33 & 26,67 & 27,00 & 36,67 \\
\hline Área de cistólito $\left(\mathrm{x}^{-3} \mathrm{~mm}^{-2}\right)$ & 4,15 & 2,45 & 1,77 & 2,80 & 2,66 & 2,77 & 2,06 & 2,19 & 2,72 & 2,25 \\
\hline Parênquima clorofiliano (\%) & 70,25 & 73,26 & 67,96 & 68,99 & 70,57 & 66,66 & 70,09 & 68,19 & 62,14 & 66,83 \\
\hline Matéria seca $(\%)$ & 28,24 & 28,84 & 29,18 & 27,50 & 27,59 & 24,05 & 26,89 & 28,31 & 29,64 & 28,29 \\
\hline Proteína bruta $(\%)$ & 20,76 & 17,42 & 16,56 & 17,23 & 15,89 & 17,30 & 17,25 & 16,45 & 15,61 & 16,15 \\
\hline Fibra bruta $(\%)$ & 8,79 & 8,40 & 10,23 & 8,53 & 9,20 & 11,32 & 9,06 & 9,90 & 9,70 & 10,86 \\
\hline Matéria mineral (\%) & 8,70 & 7,28 & 8,79 & 8,83 & 11,18 & 10,71 & 9,29 & 9,03 & 9,02 & 7,07 \\
\hline
\end{tabular}

Tabela 4. Coeficientes de correlação entre as 17 características morfo-anatômicas e bromatológicas da folha mediana (15a folha), das dez cultivares de amoreira e os dois primeiros componentes principais $\left(\mathrm{Y}_{1}\right.$ e $\left.\mathrm{Y}_{2}\right)$.

\begin{tabular}{lrr}
\hline Característica quantitativa & \multicolumn{1}{c}{$\mathrm{Y}_{1}$} & \multicolumn{1}{c}{$\mathrm{Y}_{2}$} \\
\hline Área da lâmina foliar $\left(\mathrm{cm}^{2}\right)$ & 0,5842 & 0,4356 \\
Espessura da folha $(\mu \mathrm{m})$ & $-0,4838$ & 0,6087 \\
Folhas não consumidas $(\%)$ & 0,9509 & $-0,2162$ \\
Número de nervuras secundárias & $-0,3899$ & 0,6141 \\
Área da nervura secundária $\left(\mathrm{mm}^{2}\right)$ & $-0,1096$ & 0,8719 \\
Espessura epiderme + colênquima $(\mu \mathrm{m})$ & 0,0676 & 0,9031 \\
Parênquima + floema $(\%)$ & 0,0746 & 0,0023 \\
Epiderme $(\%)$ & 0,7023 & 0,3196 \\
Idioblasto de mucilagem $\left(\mathrm{n}^{\mathrm{o}} \mathrm{mm}^{-1}\right)$ & 0,6402 & 0,5724 \\
Idioblasto de mucilagem $(\%)$ & 0,5016 & 0,7837 \\
Idioblasto cistólito $\left(\mathrm{n}^{\mathrm{0}} \mathrm{mm}^{-2}\right)$ & 0,8339 & $-0,3003$ \\
Área de cistólito $\left(\mathrm{x} 10^{-3} \mathrm{~mm}^{-2}\right)$ & $-0,4079$ & 0,7468 \\
Parênquima clorofiliano $(\%)$ & $-0,7838$ & $-0,0411$ \\
Matéria seca $(\%)$ & $-0,1038$ & $-0,3470$ \\
Proteína bruta $(\%)$ & $-0,5301$ & 0,6067 \\
Fibra bruta (\%) & 0,6578 & 0,1967 \\
Matéria mineral $(\%)$ & $-0,1897$ & $-0,1278$ \\
\hline Informação retida $(\%)$ & 41,93 & 34,17 \\
Informação acumulada $(\%)$ & - & 76,10 \\
\hline
\end{tabular}

sentar valor da informação retida maior que do segundo componente, foi também considerado mais satisfatório para explicar a contribuição das características avaliadas na formação dos agrupamentos das cultivares de amoreira, relacionadas com a qualidade da folha mediana para a alimentação das lagartas do bichoda-seda.
O dendrograma resultante da análise de agrupamento e a dispersão gráfica referente à análise dos componentes principais (Figura 2) revelaram que as características avaliadas da folha mediana, com maior poder discriminatório, foram as responsáveis pela formação de quatro grupos principais entre as cultivares de amoreira estudadas. O primeiro grupo foi formado isoladamente pela cultivar Calabresa, considerada como recomendável isoladamente pela qualidade da folha mediana. O segundo grupo, considerado também como recomendável para a alimentação do bicho-da-seda, foi constituído pelas cultivares Korin e IZ 5/2. O terceiro grupo, considerado intermediário, foi composto pelas cultivares IZ 40, IZ 64, IZ 15/7, IZ 23/3 e IZ 56/4. O quarto grupo foi formado pelas cultivares IZ 13/6 e IZ 57/2, consideradas pouco recomendáveis para o consumo das lagartas.

A análise conjunta do primeiro componente (Tabela 4) e da dispersão gráfica (Figura 2) mostrou que as folhas medianas das cultivares IZ 13/6 e IZ 57/2 apresentaram maiores porcentagens de folhas não consumidas, de fibra bruta, de epiderme e de idioblastos de mucilagem, maior número de idioblastos de cistólito e de mucilagem, bem como menor porcentagem de parênquima clorofiliano (Tabela 3). Essas cultivares, conseqüentemente, são consideradas pouco recomendáveis ao consumo. As cultivares Calabresa, Korin e IZ 5/2 apresentaram resultados diferenciados, sendo caracterizadas como recomendáveis para o consumo, constituindo-se em forrageiras com alta qualidade da folha mediana e de maior preferência pelo bicho-da-seda. 
Amaior qualidade foliar, presente na cultivar Korin, também constatada por Porto et al. (2004), revela que a alimentação de lagartas, com esta cultivar, propicia melhores desempenhos biológico e produtivo ao bicho-da-seda.

Portanto, as cultivares Calabresa (primeiro grupo), Korin e IZ 5/2 (segundo grupo) podem ser consideradas as mais apropriadas para alimentação do bicho-daseda, como também constatou Mendonça (1994), uma vez que apresentaram maior proporção de folha

A

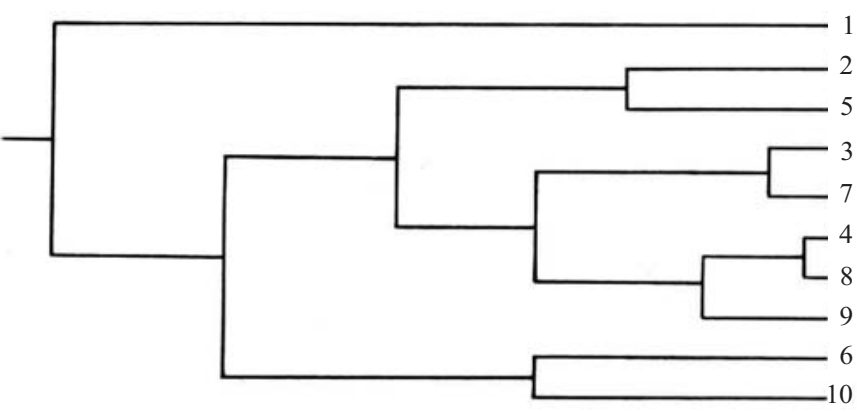

B

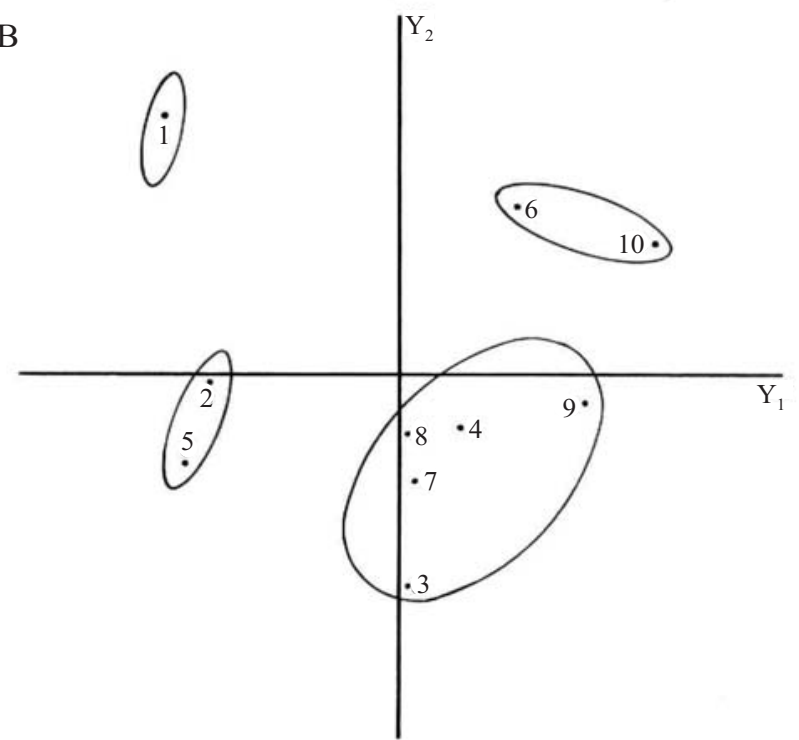

Figura 2. Dendrograma resultante da análise de agrupamento das 17 características quantitativas da folha mediana (15a), utilizando-se a distância euclidiana média entre dez cultivares de amoreira (A) e dispersão gráfica das dez cultivares de amoreira (B), utilizando-se os dois primeiros componentes principais $\left(\mathrm{Y}_{1}\right.$ e $\left.\mathrm{Y}_{2}\right)$, para o conjunto das 17 características quantitativas da folha mediana (15므). Cultivares de amoreira: Calabresa (1); Korin (2); IZ 40 (3); IZ 64 (4); IZ 5/2 (5); IZ 13/6 (6); IZ 15/7 (7); IZ 23/3 (8); IZ 56/4 (9); IZ 57/2 (10). consumida, atribuída, principalmente, à ocorrência de características quantitativas desejáveis na folha mediana (Tabela 3). Resultados diferentes foram verificados nas cultivares IZ 13/6 e IZ 57/2 (quarto grupo), que apresentaram consumo foliar reduzido, em virtude da presença de características indesejáveis na folha (Katsumata, 1971; Fahn, 1979; Fujita \& Uchikawa, 1986; Cappellozza et al., 1996; Sugimura et al., 1999). As cultivares IZ 40, IZ 64, IZ 15/7, IZ 23/3 e IZ 56/4 foram consideradas como pertencentes ao grupo intermediário, em relação à qualidade da folha mediana.

Deve-se ressaltar que na classificação das cultivares de amoreira, quanto à qualidade das folhas, não foi considerado o seu desempenho produtivo ( $\mathrm{kg} \mathrm{ha}^{-1}$ de folhas por ano).

A espessura da folha é característica importante para a manutenção da turgescência, condição imprescindível no consumo pelas lagartas do bicho-da-seda, devendose também observar essa característica na escolha das cultivares de amoreira (Hazama, 1968; Tinoco \& Almeida, 1992; Takahashi, 1996). As cultivares Calabresa e Korin caracterizaram-se pela maior espessura das folhas superior (Tabela 1) e mediana (Tabela 3), permitindo considerá-las, também por esse motivo, como as mais recomendáveis ao consumo. Esta característica contribuiu para a inclusão de Calabresa e Korin no grupo das cultivares mais consumidas pelo bicho-da-seda.

\section{Conclusões}

1. As cultivares Korin, Calabresa, IZ 5/2 e IZ 15/7 apresentam características foliares desejáveis e são as mais consumidas pelas lagartas do bicho-da-seda.

2. As cultivares IZ 13/6 e IZ 57/2 são as menos recomendáveis para o consumo e as cultivares IZ 40, IZ 64, IZ 23/3 e IZ 56/4 são consideradas intermediárias, em relação à preferência pelo bicho-da-seda e qualidade das folhas.

\section{Referências}

AKIN, D.E. Histological and physical factors affecting digestibility of forages. Agronomy Journal, v.81, p.17-25, 1989.

BRITO, C.J.F.A.; RODELLA, R.A. Caracterização morfo-anatômica da folha e do caule de Brachiaria brizantha (Hochst. ex A. Rich.) Stapf e B. humidicola (Rendle) Schweick. (Poaceae). Revista Brasileira de Botânica, v.25, p.221-228, 2002.

BRITO, C.J.F.A.; RODELLA, R.A.; DESCHAMPS, F.C. Anatomia quantitativa da folha e do colmo de Brachiaria brizantha (Hochst. ex 
A. Rich.) Stapf e B. humidicola (Rendle) Schweick. Revista Brasileira de Zootecnia, v.33, p.519-528, 2004.

BRITO, C.J.F.A.; RODELLA, R.A.; DESCHAMPS, F.C. Perfil químico da parede celular e suas implicações na digestibilidade de Brachiaria brizantha e Brachiaria humidicola. Revista Brasileira de Zootecnia, v.32, p.1835-1844, 2003.

BRITO, C.J.F.A.; RODELLA, R.A.; DESCHAMPS, F.C.; ALQUINI, Y. Anatomia caulinar de cultivares de Pennisetum purpureum Schum. (Poaceae). Arquivos de Biologia e Tecnologia, v.40, p.657-660, 1997a.

BRITO, C.J.F.A.; RODELLA, R.A.; DESCHAMPS, F.C.; ALQUINI, Y. Anatomia quantitativa e degradação in vitro de tecidos em cultivares de capim-elefante (Pennisetum purpureum Schumach.). Revista Brasileira de Zootecnia, v.28, p.223-229, 1999.

BRITO, C.J.F.A.; RODELLA, R.A.; DESCHAMPS, F.C.; ALQUINI, Y. Organização estrutural da lâmina e da bainha foliar de cultivares de capim-elefante (Pennisetum purpureum Schum. Poaceae). Arquivos de Biologia e Tecnologia, v.40, p.661-671, 1997b.

CAPPELLOZZA, L.; CORADAZZI, A.T.; CAPPELLOZZA, S.; BALDAN, B.; MARIANI, P. Studies on the phenotypic variability of seven cultivars of Morus alba L. and three of Morus multicaulis P. (Moraceae) - part 2. Sericologia, v.36, p.91-102, 1996.

CORRÊA, C.F.; RODELLA, R.A. Caracterização das fases de desenvolvimento de células gigantes induzidas por Meloidogyne exigua em raiz de seringueira (Hevea brasiliensis Muell. Arg.). Nematropica, v.32, p.131-136, 2002.

FAHN, A. Secretory tissues in plants. New York: Academic Press, 1979. 302p.

FONSECA, A. da S.; FONSECA, T.C. Cultura da amoreira e criação do bicho-da-seda: sericicultura. São Paulo: Nobel, 1988. 246p.

FONSECA, A. da S.; FONSECA, T.C.; CUNHA, E.A.; SCHAMASS, E.A. Competição de variedades, híbridos naturais e híbridos artificiais de amoreira IV. Boletim de Indústria Animal, v.44, p.329-334, 1987.

FUJITA, H.; UCHIKAWA, C. Electron microscopical study of mulberry with special reference to the identification of cultivars. In: KITAURA, K. (Ed.). Development of new technology for identification and classification of tree crops and ornamentals. Yatabe-cho, Tsukuba-gun, Ibaraki-ken, Japan: Fruit Tree Research Station, Ministry of Agriculture Forestry and Fisheries, 1986. p.25-29.

GERRITS, P.O. The application of glycol methacrylate in histotechnology: some fundamental principles. Netherlands: Department of Anatomy and Embriology, State University of Groningen, 1991. 80p.

HAMANO, K.; OKANO, T. Effects of dietary levels of protein and pyridoxine growth of younger larvae of the silkworm Bombyx mori. Journal of Sericultural Science of Japan, v.58, p.203-208, 1989.

HANADA, Y.; WATANABE, J.K. Manual de criação do bichoda-seda. Curitiba: Cocamar, 1986. 224p.
HAZAMA, K. Breeding of mulberry tree. Japan Agricultural Research Quarterly, v.3, p.15-19, 1968.

HIRANO, H. Varietal differences of leaf protein profiles in mulberry. Phytochemistry, v.21, p.1513-1518, 1982.

IDE, S. Efeito da composição mineral das folhas de amoreira sobre o crescimento do bicho-da-seda. Fertilité, v.33, p.3-18, 1969.

JOHANSEN, D.A. Plant microtechnique. New York: McGrowHill Book, 1940. 523p.

JUNG, H.G.; ALLEN, M.S. Characteristics of plant cell walls affecting intake and digestibility of forages by ruminants. Journal of Animal Science, v.73, p.2774-2790, 1995.

KATSUMATA, F. Shape of idioblasts in mulberry leaves with special reference to the classification of mulberry trees. Journal of Sericultural Science of Japan, v.40, p.313-322, 1971.

MENDONÇA, G.A. Utilização de híbridos de amoreira na produção de casulos do bicho-da-seda (Bombyx mori L.). 1994. 59p. Dissertação (Mestrado) - Escola Superior de Agricultura Luiz de Queiroz, Piracicaba.

METCALFE, C.R.; CHALK, L. Anatomy of the dicotyledons. Oxford: Clarendon Press, 1957. v.1, p.1259-1271.

MIRANDA, J.E.; BONACIN, G.A.; TAKAHASHI, R. Produção e qualidade de folhas de amoreira em função da época do ano e de colheita. Scientia Agricola, v.59, p.499-504, 2002.

O’BRIEN, T.P.; FEDER, N.; McCULLY, M.E. Polychromatic staining of plant cell walls by toluidine blue. Protoplasma, v.59, p.367-373, 1964.

OKINO, I. Manual de sericicultura. Bauru: Abraseda, 1982. 80p. PERIASAMY, K.; RADHAKRISHNAN, S. A quantitative study of food utilization and silk production in Bombyx mori L. for evaluation of superior varieties of mulberry. Sericologia, v.25, p.491-500, 1985. PORTO, A.J.; FUNARI, S.R.C.; DIERCKX, S.M.A.G. Avaliação da idade de corte de dois cultivares de amoreira nos desempenhos biológico e produtivo do bicho-da-seda (Bombix mori L.). Revista de Educação Continuada do CRMV-SP, v.7, p.55-65, 2004.

PORTO, A.J.; OKAMOTO, F. Sistemas de utilização de dois cultivares de amoreira em duas idades de crescimento vegetativo, no desempenho do bicho-da-seda (Bombyx mori L.). Boletim de Indústria Animal, v.57, p.171-178, 2000.

QADER, M.A. Effects of mulberry leave quality on fibroin content in the posterior silkgland of Bombyx mori L. Bangladesh Journal of Zoology, v.23, p.229-232, 1995.

RODELLA, R.A.; AYOUB, J.; MAIMONI-RODELLA, R.C.S. Estudo quantitativo de características anatômicas da folha de Panicum maximum Jacq. e Panicum coloratum L. Revista de Agricultura, v.59, p.163-174, 1984.

RODELLA, R.A.; ISHIY, C.M.; MAIMONI-RODELLA, R.C.S.; AMARAL JUNIOR, A. Estudo quantitativo de características anatômicas da folha de duas espécies de Brachiaria. Agrociência, v.2, p.21-30, 1982.

SCRIBER, J.M.; SLANSKY JUNIOR, F. The nutritional ecology of immature insects. Annual Review of Entomology, v.26, p.183-211, 1981.

SILVA, D.J. Análises de alimentos: métodos químicos e biológicos. Viçosa: UFV, 1981. 166p. 
SNEATH, P.H.A.; SOKAL, R.R. Numerical taxonomy: the principles and practice of numerical classification. San Francisco: W. H. Freeman, 1973. 573p.

SUGIMURA, Y.; MORI, T.; NITTA, I.; KOTANI, E.; FURUSAWA, T.; TATSUMI, M.; KUSAKARI, S.I.; WADA, M.; MORITA, Y. Calcium deposition in idioblasts of mulberry leaves. Annals of Botany, v.83, p.543-550, 1999.

TAKAHASHI, R. Características vegetativas e nutricionais de cultivares de amoreira utilizados na alimentação do bicho-daseda (Bombyx mori L.). 1996. 118p. Tese (Livre Docência) Universidade Estadual Paulista, Jaboticabal.

TAKAHASHI, R.; KRONKA, R.N. Efeito dos diferentes tipos de adubação na produção de amoreira (Morus alba L.). Boletim de Indústria Animal, v.46, p.157-164, 1989.
THANGAMANI, R.; VIVEKANANDAN, M. Physiological studies and leaf nutrient analysis in the evaluation of best mulberry variety. Sericologia, v.24, p.317-324, 1984.

TINOCO, S.T.J.; ALMEIDA, R.A.C. Manual de sericicultura. Campinas: CATI, 1992. 59p. (Manual, 35).

VENTRELLA, M.C.; RODELLA, R.A.; COSTA, C.; CURI, P.R. Anatomia e bromatologia de espécies forrageiras de Cynodon Rich. I. Folha. In: REUNIÃO DA SOCIEDADE BRASILEIRA DE ZOOTECNIA, 34., 1997, Juiz de Fora. Anais. Juiz de Fora: SBZ, 1997. p.3-5.

WILSON, J.R. Organization of forage plant tissues. In: JUNG, H.G; BUXTON, D.R.; HATFIELD, R.D.; RALPH, J. (Ed.). Forage cell wall structure and digestibility. Madison, Wisconsin: ASA: CSSA: SSSA, 1993. p.1-32.

Recebido em 8 de julho de 2004 e aprovado em 5 de setembro de 2005 